\title{
Loss of Complex I due to Mitochondrial DNA Mutations in Renal Oncocytoma
}

\author{
Johannes A. Mayr, ${ }^{1}$ David Meierhofer, ${ }^{1}$ Franz Zimmermann, ${ }^{1}$ Rene Feichtinger, ${ }^{1}$ Christian Kögler, ${ }^{3}$ \\ Manfred Ratschek, ${ }^{3}$ Nikolaus Schmeller, ${ }^{2}$ Wolfgang Sperl, ${ }^{1}$ and Barbara Kofler ${ }^{1}$
}

\begin{abstract}
Purpose: Many solid tumors exhibit abnormal aerobic metabolism characterized by increased glycolytic capacity and decreased cellular respiration. Recently, mutations in the nuclear encoded mitochondrial enzymes fumarate hydratase and succinate dehydrogenase have been identified in certain tumor types, thus demonstrating a direct link between mitochondrial energy metabolism and tumorigenesis. Although mutations in the mitochondrial genome (mitochondrial DNA, mtDNA) also can affect aerobic metabolism and mtDNA alterations are frequently observed in tumor cells, evidence linking respiratory chain deficiency in a specific tumor type to a specific mtDNA mutation has been lacking.

Experimental Design: To identify mitochondrial alterations in oncocytomas, we investigated the activities of respiratory chain enzymes and sequenced mtDNA in 15 renal oncocytoma tissues.

Results: Here, we show that loss of respiratory chain complex I (NADH/ubiquinone oxidoreductase) is associated with renal oncocytoma. Enzymatic activity of complex I was undetectable or greatly reduced in the tumor samples $(n=15)$. Blue Native gel electrophoresis of the multisubunit enzyme complex revealed a lack of assembled complex I. Mutation analysis of the mtDNA showed frame-shift mutations in the genes of either subunit ND1, ND4, or ND5 of complex I in 9 of the 15 tumors.

Conclusion: Our data indicate that isolated loss of complex $I$ is a specific feature of renal oncocytoma and that this deficiency is frequently caused by somatic mtDNA mutations.
\end{abstract}

A shift in cellular energy production from aerobic oxidation in mitochondria to anaerobic glycolysis is a fundamental property of cancer cells, also called the Warburg effect $(1,2)$. Otto Warburg postulated that damage of the aerobic energy metabolism is a primary and irreversible event in tumor formation (2). Recently, this hypothesis has been supported by the demonstration that mutations of single enzymes of the mitochondrial energy metabolism are associated with tumorigenesis $(3,4)$. Germline mutations in distinct subunits of

\footnotetext{
Authors' Affiliations: Departments of ${ }^{1}$ Pediatrics and ${ }^{2}$ Urology, University Hospital Salzburg, Paracelsus Medical University, Salzburg, Austria and ${ }^{3}$ Institute of Pathology, Medical University of Graz, Graz, Austria

Received 9/4/07; revised 11/13/07; accepted 11/28/07

Grant support: Children's Cancer Foundation Salzburg, Vereinigung zur Förderung der pädiatrischen Forschung und Fortbildung Salzburg, Oesterreichische Nationalbank Jubiläumsfonds project 12568, Paracelsus Medical University project 06/04/022, and Austrian Genome Program GEN-AU.

The costs of publication of this article were defrayed in part by the payment of page charges. This article must therefore be hereby marked advertisement in accordance with 18 U.S.C. Section 1734 solely to indicate this fact.

Note: Supplementary data for this article are available at Clinical Cancer Research Online (http://clincancerres.aacrjournals.org/).

J.A. Mayr and D. Meierhofer contributed equally to this work.

Requests for reprints: Wolfgang Sperl, Department of Pediatrics, University Hospital Salzburg, Paracelsus Medical University, Muellner Hauptstrasse 48, A-5020 Salzburg, Austria. Phone: 43-662-4482-2600; Fax: 43-662-44822604; E-mail: w.sperl@salk.at.

(C) 2008 American Association for Cancer Research.

doi:10.1158/1078-0432.CCR-07-4131
}

succinate dehydrogenase predispose to hereditary paragangliomas and pheochromocytomas $(4,5)$. Germline mutations in the fumarate hydratase gene can either cause leiomyoma, leiomyosarcoma, and renal cell carcinoma (3) or Leydig cell tumor (6). Therefore, succinate dehydrogenase and fumarate hydratase are regarded as mitochondrial tumor suppressors for these types of tumors (5).

Mitochondrial DNA (mtDNA), the small genome of the mitochondrion, is essential for aerobic energy metabolism and encodes some of the subunits of respiratory chain complexes I, III, and IV, as well as the $\mathrm{F}_{1} \mathrm{~F}_{0}$-ATP synthase. Complex I consists of 46 different subunits, with a molecular mass totaling $980 \mathrm{kDa}$. Seven of these subunits (ND1-ND6 and ND4L) are encoded by mtDNA; the other complex I genes are located on nuclear chromosomes.

Because of its essential role in energy metabolism, the mitochondrial genome has long been suspected of contributing to metabolic alterations in tumors. Such investigations date back to the 1960s, and in fact, numerous somatic mtDNA mutations have been reported in various types of human tumors $(7-10)$. Evidence that dysfunction of enzymes of the respiratory chain, resulting from mutations in mtDNA, plays a role in tumorigenesis is based on in vitro data of cultured cells but has not been shown directly in tumor tissues $(10,11)$. Recently, Gasparre et al. have reported that somatic mutations of mtDNA encoded subunits of complex I are statistically significantly associated with thyroid oncocytoma (12). However, no data of the functional consequence on complex I activity of these potentially disruptive mutations have been 
presented (12). No other direct association of somatic mtDNA mutations with a distinct tumor type and pathophysiology has been published thus far $(5,13)$.

Renal oncocytomas are usually benign tumors accounting for $\sim 5 \%$ of all renal cell neoplasias. A characteristic feature of oncocytomas is the accumulation of a large number of mitochondria (14). This hyperproliferation of mitochondria was first found in thyroid tumors (Hürthle cell carcinoma) and was called an oxyphilic change in the cells. Oxyphilic tumors are also known for various other organs; however, the cause of the hyperproliferation of mitochondria is unknown. In analogy to other known defects of the mitochondrial energy metabolism, a compensatory feedback mechanism leading to proliferation of this organelle has been proposed (15).

Previous studies using restriction length polymorphism analysis have provided contradictory data on mtDNA alterations in renal oncocytomas $(16-18)$, although to our knowledge a systematic search for mutations in the mitochondrial genome has not been reported. Thus, proof of a direct association of mtDNA mutations, biochemistry, and tumorigenesis has been lacking. To elucidate the cause of the mitochondrial alterations in oncocytomas, we investigated the activities of respiratory chain enzymes and screened for mtDNA mutations in renal oncocytomas.

\section{Materials and Methods}

Patients. Fifteen renal oncocytoma tissue samples (mean age $61.5 \mathrm{y}$, range $29-77 \mathrm{y} ; 66 \%$ male) were obtained from the Biobank of the Medical University of Graz and Department of Urology, University Hospital Salzburg. All tissues were frozen and stored in liquid nitrogen within $20 \mathrm{~min}$ after surgery. Tumor cell content and cellular composition of samples were evaluated using H\&E-stained frozen sections. Corresponding unaffected kidney tissue was available from patients $6,8,12,13,14$, and 15 . In addition, 14 age-matched nonneoblastic kidney samples (mean age $61.8 \mathrm{y}$, range $35-74$ y; $60 \%$ male) were included as controls for enzymatic measurements (19). The study was approved by the ethical committee of Medical University of Graz.

Spectrophotometric detection of enzyme activities. Renal oncocytoma and control kidney tissues (20-100 mg) were homogenized with a tissue disintegrator (Ultraturrax, IKA) in extraction buffer $[20 \mathrm{mmol} / \mathrm{L}$ Tris-HCl (pH 7.6), $250 \mathrm{mmol} / \mathrm{L}$ sucrose, $40 \mathrm{mmol} / \mathrm{L} \mathrm{KCl}, 2 \mathrm{mmol} / \mathrm{L}$ EGTA] and finally homogenized with a motor-driven Teflon-glass homogenizer (Potter S, Sartorius). The homogenate was centrifuged at $600 \times \mathrm{g}$ for $10 \mathrm{~min}$ at $4^{\circ} \mathrm{C}$. The postnuclear supernatant containing the mitochondrial fraction was used for measurement of enzyme activities, Blue Native PAGE (BN-PAGE) and immunoblot analysis. The rotenone-sensitive complex I activity was measured spectrophotometrically as $\mathrm{NADH} /$ decylubiquinone oxidoreductase at $340 \mathrm{~nm}$ (20). The enzyme activities of citrate synthase, complex IV (ferrocytochrome $c$ /oxygen oxidoreductase), and the oligomycin-sensitive ATPase activity of the $\mathrm{F}_{1} \mathrm{~F}_{0}$ ATP synthase were determined as reported previously (19).

BN-PAGE and immunoblot analysis. Solubilized mitochondrial membranes were prepared from post nuclear supernatant $(30 \mu \mathrm{g}$ protein) of kidney and oncocytoma tissues, as described previously (21). Briefly, post nuclear supernatants were sedimented by centrifugation at $13,000 \times \mathrm{g}$ for $15 \mathrm{~min}$. Membranes were solubilized with $1.5 \%$ laurylmaltoside for $15 \mathrm{~min}$ and centrifuged for $20 \mathrm{~min}$ at $13,000 \times g$. Solubilized membranes were loaded on a $5 \%$ to $13 \%$ polyacrylamide gradient gel and separated electrophoretically. The in-gel activity assay of complex I and cytochrome $c$ oxidase were done as previously described (22).
For immunoblot analysis, membrane preparations were separated by BN-PAGE (5-13\%) and blotted onto polyvinylidene difluoride membrane (Hybond-P, GE Healthcare) using a CAPS buffer $[10 \mathrm{mmol} / \mathrm{L}$ 3-[cyclohexylamino]-1-propane sulfonic acid ( $\mathrm{pH} 11$ ), 10\% methanol]. The membrane was washed in $100 \%$ methanol for $2 \mathrm{~min}$ and blocked for $1 \mathrm{~h}$ at room temperature in $5 \%$ fat-free milk powder dissolved in TBS. The primary antibody, diluted in $1 \%$ milk powder-TBS, was added overnight at $4{ }^{\circ} \mathrm{C}$. The following primary antibody dilutions were used: complex I subunit NDUFA9 monoclonal antibody (1:480; MitoSciences) and complex $\mathrm{V}$ subunit $\alpha$ monoclonal antibody (1:100,000; MitoSciences). After extensive washing, blots were incubated for $2 \mathrm{~h}$ with antimouse IgG POD-labeled antibody (Lumi-Light ${ }^{\text {Plus }}$ Western blotting kit, Roche) diluted 1:400. Detection was carried out with LumiLight $^{\text {PLUS }}$ POD substrate (Roche). After detection of complex I subunit NDUFA9, the polyvinylidene difluoride membrane was washed twice in stripping buffer [25 mmol/L Glycin-HCl (pH 2), 2\% SDS] for $10 \mathrm{~min}$, and a subsequent immunodetection with complex $\mathrm{V}$ subunit $\alpha$ antibody was done as described above.

mtDNA analysis. DNA was isolated from tissues by proteinase $\mathrm{K}$ digestion followed by phenol/chloroform extraction. The mtDNA of ND and tRNA genes was amplified using overlapping PCR fragments (23). All samples were sequenced using a GenomeLab SNP-Primer Extension kit (Beckman Coulter). Mutations were analyzed with the Beckman software investigator. Exact positions of mutations and amino acid changes were defined with the mitoAnalyzer tool (MitoAnalyzer $2000)^{4}$, using the mtDNA Genbank sequence J01415.1 as reference.

Determination of mutational load of the A3243G mutation. The percentage of mutational load was quantified by densitometry of ethidium bromide-stained agarose gels, as described previously (24).

\section{Results}

Enzymatic and immunoblot analyses of the respiratory chain in renal oncocytomas. The enzyme activities of complexes I, IV, and $\mathrm{V}$ of the respiratory chain, which consist of mitochondrial and nuclear encoded subunits, and citrate synthase, an enzyme of the Krebs cycle, were investigated in postnuclear supernatants from 15 oncocytoma tissues. Activities of complexes IV and $\mathrm{V}$, as well as citrate synthase in the oncocytomas, were found to be increased 3-fold to 7 -fold, compared with unaffected kidney cortex samples (Fig. 1; Table 1). In striking contrast, the activity of complex I was below the detection limit of $<3 \mathrm{nmol} / \mathrm{min} / \mathrm{mg}$ protein in eight oncocytomas (Fig. 1; Table 1). The other samples showed a residual activity of complex I of $<25 \%$ compared with kidney control samples (Table 1). If the samples showing residual complex I activity are compared with the activity of citrate synthase, a marker enzyme of mitochondrial energy metabolism (25), the relative enzyme activity of complex I, is $<5 \%$ compared with normal kidney. This striking reduction of complex I activity was also found by activity-staining of BN-PAGE (Fig. 2A and Supplementary Fig. S1). None of the tumor samples showed any detectable activity compared with their corresponding tumor tissue. Activity-staining of cytochrome $c$ oxidase underlines the upregulation of complex IV in renal oncocytoma as measured photometrically (Fig. 2B).

Immunoblot analysis of BN-PAGE samples revealed lack of assembled complex I (Fig. 2C) in the tumor tissues, whereas staining of the same blot with complex $\mathrm{V}$ antibodies reflects the high enzyme activity of this complex measured photometrically (Fig. 2D).

\footnotetext{
${ }^{4}$ http://www.cstl.nist.gov/biotech/strbase/mitoanalyzer.html
} 
A

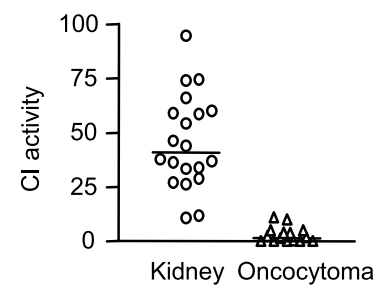

C

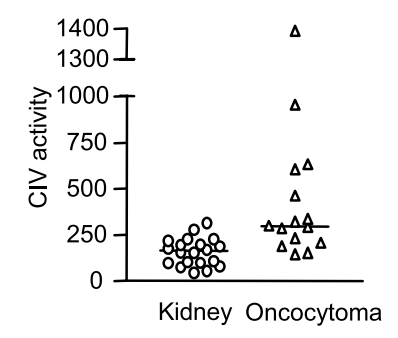

B

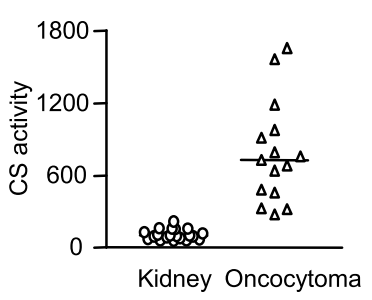

D

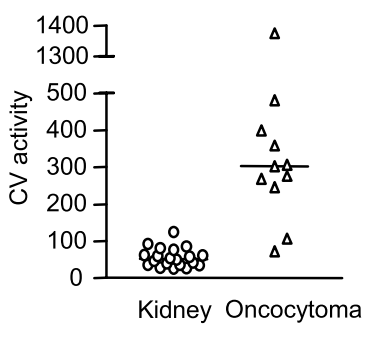

Fig. 1. Enzyme activities (nmol/min/mg protein) of complex I $(C /)$, complex IV $(C I V)$, complex $V(C V)$, and citrate synthase $(C S)$ in oncocytomas were compared with renal kidney cortex of controls. $A$, in contrast to the normal kidney tissues $(n=20)$, complex I enzyme activity in oncocytoma tissues $(n=15)$ was found to be $\langle 11 \mathrm{nmol} / \mathrm{min} / \mathrm{mg}$ protein. $B$, citrate synthase enzyme activity of oncocytomas was significantly increased compared with controls $(P<0.0001)$. Complex IV $(C ; P=0.0014)$ and complexV $(D ; P=0.0002)$ enzyme activities of oncocytomas were also higher than in controls. For the measurement of complex $V$ enzyme activity, only tumors of 11 patients were available. An unpaired $t$ test was used for statistical analysis.

Mutation analysis of the mtDNA in renal oncocytomas. To elucidate the genetic basis for the loss of complex I, we sequenced all seven mitochondrially encoded complex I genes and noticed frame-shift mutations in either the ND1, ND4 or ND5 gene in 9 of the 15 tumors with no detectable wild-type

mtDNA (Table 1; Fig. 3). Insertion of a cytosine residue into a stretch of six cytosines at mtDNA positions 3566 to 3571 was detected in the ND1 gene in tumor tissues of cases 1, 2, and 14 (Table 1). In case 3, a deletion of one cytosine in the same polycytosine stretch was identified. All four of these mutations cause termination of translation in the first third of the protein. In case 4 , we noticed an insertion of a cytosine residue in a stretch of six cytosines at positions 10947 to 10952 of the ND4 gene. This insertion causes a frame-shift and creates a stop codon $\sim 150$ bp downstream, which results in a truncated ND4 protein. In cases 5 and 6 , deletions of one adenine in a stretch of seven adenine residues (11032-11038) were found, which results in premature termination of translation of ND4. Two other insertion mutations-in cases 7 and 8-affect the same stretch of six cytosine residues (12385-12390) of the ND5 gene. In case 7 , an insertion of one thymine directly before the homopolymeric sequence was identified; in case 8 , an extra cytosine was added to the polycytosine run. Both of these frame-shift mutations create a stop codon within the first $10 \%$ of the ND5 gene. Remarkably, tissue 7 and tissue 1 originate from the same patient with two independent oncocytomas. Oncocytoma number 7 was excised from the right kidney 18 months after oncocytoma number 1 was surgically removed from the left kidney. To exclude the possibility of sample mixup, we also sequenced the displacement loop of the mtDNA of these samples and found identical sequences in both, confirming that they are indeed derived from the same individual. The matching normal kidney cortex of cases 6, 8, and 14 revealed no preexisting mutation (Fig. 3). A leucine-to-proline substitution in the ND5 subunit caused by a transition mutation at nucleotide position 13493 was observed in case 9 (Table 1). The effect of this amino acid change on the structure of the ND5 subunit is not known, although the alteration could be severe enough to disrupt the catalytic activity of the entire complex. Finally, an A-to-G transition at position 3243 in the gene encoding tRNA ${ }^{\text {Leu(UUR) }}$ was detected in case 13. RFLP analysis revealed $>95 \%$ mutational load in the oncocytoma

Table 1. Enzymes activities and mtDNA mutations in renal oncocytomas and control kidneys

\begin{tabular}{|c|c|c|c|c|c|c|c|}
\hline Case & Complex I & Citrate Synthase & Complex IV & Complex V & $\begin{array}{l}\text { mtDNA } \\
\text { mutation* }\end{array}$ & $\begin{array}{l}\text { Affected } \\
\text { genes }\end{array}$ & $\begin{array}{l}\text { Protein } \\
\text { change }\end{array}$ \\
\hline 1 & $<3$ & 791 & 205 & 481 & 3571_3572insC & ND1 & Leu89fs \\
\hline 2 & 4 & 1.656 & 1.393 & 107 & 3571_3572insC & ND1 & Leu89fs \\
\hline 3 & $<3$ & 727 & 285 & n.d. & 3571 delC & ND1 & Leu89fs \\
\hline 4 & $<3$ & 316 & 336 & 1375 & 10952_10953insC & ND4 & Leu65fs \\
\hline 5 & $<3$ & 1.565 & 323 & 71 & $11038 \overline{d e l} \mathrm{~A}$ & ND4 & Lys93fs \\
\hline 6 & 5 & 684 & 632 & 359 & 11038 delA & ND4 & Lys93fs \\
\hline 7 & $<3$ & 324 & 151 & 268 & 12384_12385insT & ND5 & Pro17fs \\
\hline 8 & 4 & 1.184 & 298 & n.d. & 12390_12391insC & ND5 & Ile19fs \\
\hline 9 & $<3$ & 481 & 142 & 276 & $\mathrm{~T} 1349 \overline{3} \mathrm{C}$ & ND5 & Leu386Pro \\
\hline 10 & $<3$ & 975 & 292 & n.d. & - & - & - \\
\hline 11 & $<3$ & 456 & 188 & n.d. & - & - & - \\
\hline 12 & 5 & 275 & 232 & 306 & - & - & - \\
\hline 13 & 10 & 910 & 604 & 246 & A3243G & tRNALeu(UUR) & - \\
\hline 14 & 5 & 638 & 461 & 399 & 3571_3572insC & ND1 & Leu89fs \\
\hline 15 & 11 & 753 & 952 & 303 & - & - & - \\
\hline Oncocytoma, mean \pm SD & $3 \pm 1$ & $782 \pm 109$ & $433 \pm 89$ & $381 \pm 106$ & & & \\
\hline Kidney, mean $\pm \mathrm{SD}(n=20)$ & $46 \pm 5$ & $111 \pm 9$ & $157 \pm 17$ & $56 \pm 6$ & & & \\
\hline
\end{tabular}

NOTE: Enzyme activity (nmol/min/mg protein) of complex I, citrate synthase, complex IV, and complex V.

Abbreviation: n.d., not determined (lack of sample).

*Positions of mutations refer to the mtDNA sequence Genbank accession number J01415.1. 


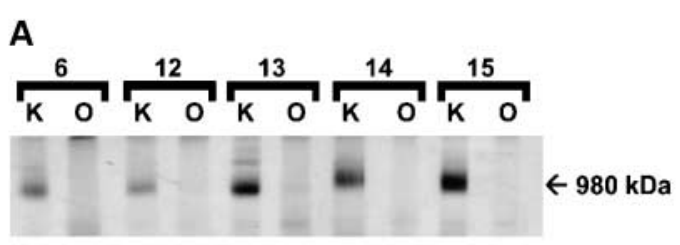

B

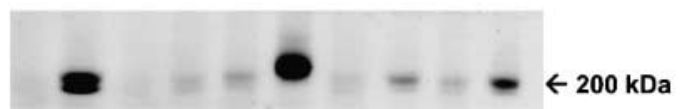

C

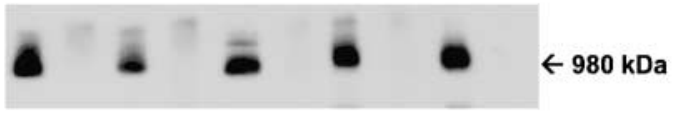

D

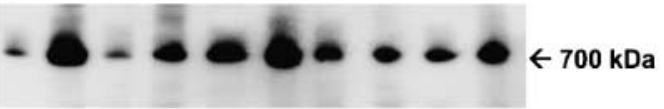

Fig. 2. BN-PAGE analysis of the complex I assembly in renal oncocytomas compared with normal kidney tissue. Mitochondrial membranes were isolated from kidney and oncocytoma tissues and subjected to one-dimensional BN-PAGE analysis. In-gel activity staining for complex I $(A)$ and complex IV $(B)$. $C$, immunoblot analysis using an antibody directed against the nuclear encoded complex I subunit NDUFA9 of the same cases. $D$, immunoblot analysis after stripping the blot shown in $C$ with an antibody directed against the nuclear encoded subunit $\alpha$ of complex V. K, normal kidney; $\mathrm{O}$, renal oncocytoma tissue; numbers refer to cases as summarized in Table 1. Full-length blots/gels are presented in Supplementary Fig. S1.

tissue, but the mutation was also detectable in the normal kidney tissue with a $20 \%$ mutational load (data not shown). Interestingly, the same mutation is a frequent cause of MELAS (mitochondrial myopathy, encephalomyopathy, lactic acidosis, and stroke-like episodes) syndrome. In the remaining four cases, screening of all mtDNA-encoded complex I and mitochondrial tRNA genes did not reveal any somatic mutation with pathogenic potential.

\section{Discussion}

Here, we provide the first report that renal oncocytomas show a loss of complex I of the respiratory chain, which is frequently caused by mutations of the mtDNA. Somatic mutations of the mtDNA have been reported in a number of different tumor types $(7,8,13)$. However, most of these mutations were silent without an apparent pathogenic potential and a role for mtDNA in tumor development has not been established yet (5). Recently, an association of somatic mtDNA mutations with the oncocytic phenotype of thyroid tumors has been reported (12). Two types of frame-shift mutations (3571_3572insC; 11038delA) detected in thyroid oncocytomas have also been detected in the present study in renal oncocytoma tissues. Our data now provide also the functional consequence of these mutations by showing loss of enzyme activity and assembly of complex I.

We note that a previous study found an $\sim 50 \%$ reduction in complex I activity in renal oncocytomas (26). Residual complex I activity found in that study may have been due to con- tamination of investigated tumor tissues with normal kidney tissue and epithelial cells of vessels. To avoid such contamination, we validated cryostat sections of tumor tissues histologically before using adjacent sections for biochemical and genetic investigations. In addition to photometric measurement of complex I, we substantiated our findings by complex I activity-staining and immunoblot analysis of Blue Native gels.

The biochemical consequences of the A3243G mutation of case 13 are in agreement with the decreased activity of complex I reported in muscle biopsies and fibroblasts of patients carrying this mutation (27). The A3243G mutation might be sporadically associated with other tumor types because it was also detected in a colon cancer sample (28) and a renal cell carcinoma (24).

The frame-shift mutations detected in this study are predicted to cause termination of translation in the first third of the corresponding proteins. Similar mutations are known to affect not only the enzyme activity, but also the assembly of complex I (29), which is consistent with our biochemical and immunoblot data. Homopolymeric stretches (5-8-bp long) in mtDNA are known hotspots for base pair insertions and deletions (30). Interestingly, several of these mtDNA repeat mutations were reported in different tumors in earlier studies (Fig. 4). Because no respiratory chain activity measurements were reported in those tumors, it is difficult to evaluate the effect of those mutations on mitochondrial energy metabolism

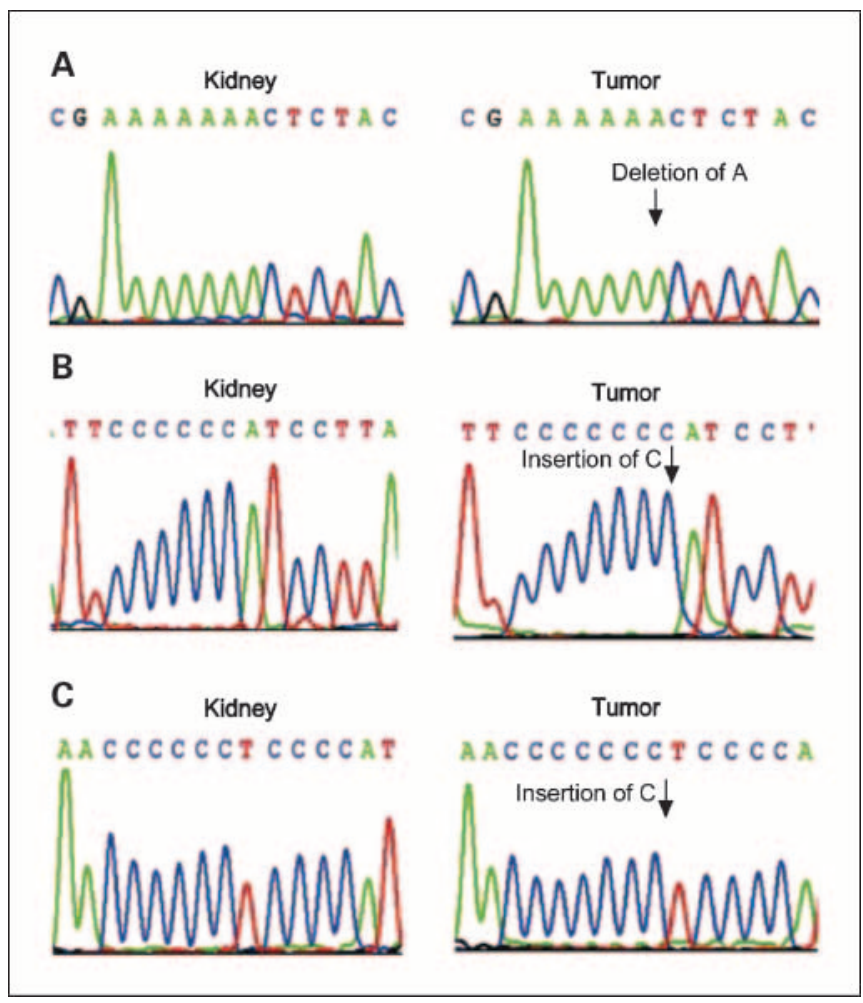

Fig. 3. Sequence analysis of mtDNA-encoded complex I genes in oncocytomas and matched kidney tissues. $A$, in case 6 , a homopolymeric stretch at positions 11032 to 11038 in the ND4 gene displayed seven adenine residues in the normal kidney tissue and six adenine residues in the oncocytoma tissue. $B$, a homopolymeric stretch of cytosines at positions 12385 to 12390 in the ND5 gene in case 8 showed six residues in the kidney cortex tissue and seven in the corresponding tumor tissue. $C$, sequence analysis of case 14 shows six cytosines at positions 3566 to 3571 in the normal tissue and seven cytosines in the tumor tissue. 


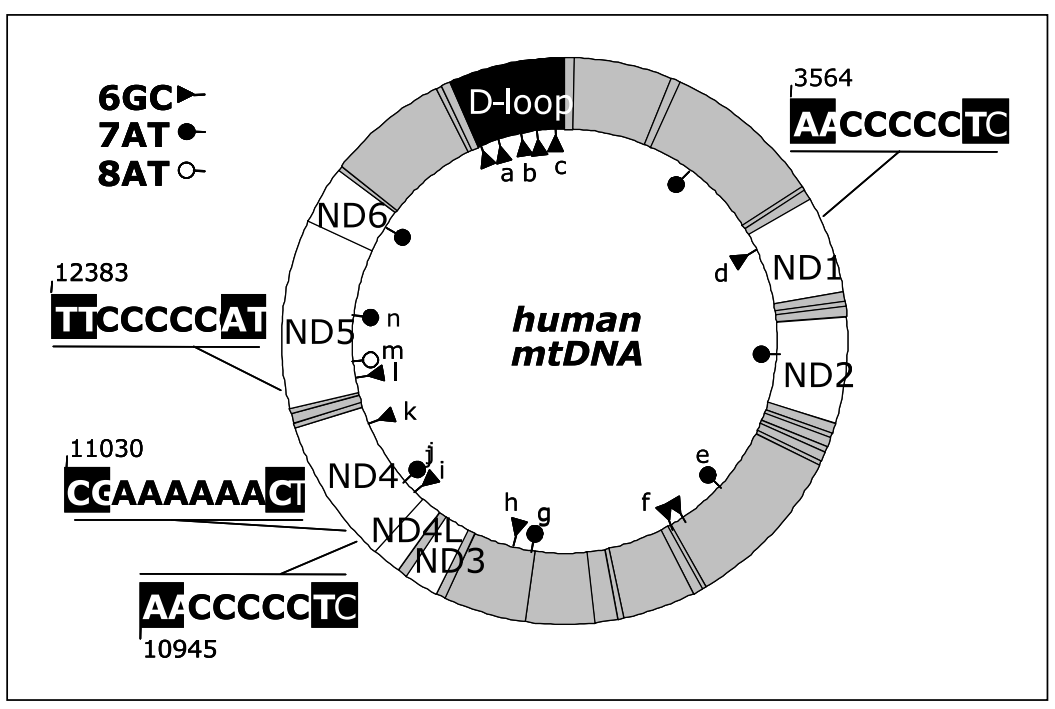

Fig. 4. Localization of homopolymeric six G-C and seven to eight $A-T$ base pair repeats within the human mtDNA (reference sequence: Genbank J01415.1) and illustration of the sequence motifs where insertions or deletions were found in the investigated oncocytoma tissues. The motifs where mutations in these repeats have been reported previously are annotated as follows: (a) displacement loop (D-loop) $(39-42),(b)$ displacement loop (39), (c) displacement loop (42), (d) ND1 $(12,43$, this study cases $1-3,14),(e)$ COX1 (43), $(f)$ tRNA ${ }^{\text {Ser(AGY) }}$ $(44,45),(g)$ COX3 (39), (h) COX3 (46), (i) ND4 (29, this study case 4), (j) ND4 (12, this study cases 5-6), (k) ND4 (47), (/) ND5 (43, this study cases 7-8), (m) ND5 $(43,47,48)$ (n) ND5 (12).

and their role in tumorigenesis, especially in cases of high mutation load.

We hypothesize that the four oncocytomas in our study with no detected pathogenic mutations in mtDNA (cases 10-12 and 15; Table 1) may have mutations in 1 of the 39 known nuclear genes encoding complex I subunits or assembly factors (31). Loss of heterozygosity in combination with such a nuclear mutation would be expected to lead to impairment of complex I, and observations of frequent cytogenetic abnormalities in oncocytomas lend support to this idea (32).

Oncocytomas occasionally appear in both kidneys. Interestingly, in one such case, distinct cytogenetic backgrounds were found in each tumor (32). A similar case with two independent oncoytomas was included in our study, wherein oncocytomas were excised first from the left (case 1) and then from the right kidney (case 7) over an interval of 18 months. As in the aforementioned study (32), these tumors were distinct from each other, and they carried different frame-shift mutations in the mtDNA. We can only speculate as to whether the induction of these tumors is due to an environmental trigger or to a genetic predisposition in such patients.

Patients with Birt-Hogg-Dube syndrome have an increased incidence of renal tumors, including renal oncocytomas (33). However, a function for the $B D H$ (folliculin) gene, which is thought to be responsible for this syndrome, has not yet been determined. One possibility is that this protein is involved in cellular energy metabolism (34). Recently, somatic missense mutations in the complex I assembly protein GRIM-19 were identified in $15 \%$ of sporadic oxyphil Hurthle cell tumors of the thyroid (35), suggesting that impairment of complex I activity may be associated with oxyphilic tumors generally and not just renal oncocytomas. Further biochemical and genetic support for this possibility comes from the recent description of a combined reduction in the activities of complexes I and III in a cell line derived from an oncocytic thyroid follicular carcinoma. The reduction of complex I activity in that tumor was caused by a frame-shift mutation in the ND1 gene (36), which is also what we observed in cases 1 and 2 of our study.

Recently, it was shown that complex I is an integral component of apoptotic pathways. The nuclear encoded subunit NDUFS1, which is part of the iron-sulfur clusters of complex I, is proteolytically cleaved by caspase-3 (37). Therefore, complex I seems to have a dual function-creating a proton gradient under normal conditions and participating in apoptosis after caspase-3 cleavage. Loss of this intermediate step of apoptosis due to a deficiency of complex I might lead to a selective advantage for tumor cells. We envisage that in cells lacking functional complex I, apoptosis is attenuated, which in turn would favor tumor formation. In support of this hypothesis, Shidara et al. showed that pathogenic mutations in the mitochondrial ATPG gene contribute to promotion of cancer by prevention of apoptosis (38).

Our findings reveal that isolated deficiency of complex I besides high activity of the other OXPHOS enzymes can be regarded as a specific feature of renal oncocytoma. Our results also support the hypothesis of Otto Warburg, proclaimed $>80$ years ago, that irreversible damage to aerobic cellular respiration is an important event in tumor development (2).

\section{Acknowledgments}

We thank K. Zatloukal for the critical reading of the manuscript and I. Kufferath and D. Radmayr for technical assistance.

\section{References}

1. Garber K. Energy boost: the Warburg effect returns in a new theory of cancer. J Natl Cancer Inst 2004:96: 1805-6.

2. Warburg O. On the origin of cancer cells. Science 1956;123:309-14

3. Tomlinson IP, Alam NA, Rowan AJ, et al. Germline mutations in $\mathrm{FH}$ predispose to dominantly inherited uterine fibroids, skin leiomyomata and papillary renal cell cancer. Nat Genet 2002;30:406-10.
4. Baysal BE, Ferrell RE, Willett-Brozick JE, et al Mutations in SDHD, a mitochondrial complex II gene, in hereditary paraganglioma. Science 2000;287: $848-51$.

5. Gottlieb E, Tomlinson IP. Mitochondrial tumour suppressors: a genetic and biochemical update. Nat Rev Cancer 2005:5:857-66.

6. Carvajal-Carmona LG, Alam NA, Pollard PJ, et al. Adult leydig cell tumors of the testis caused by germ- line fumarate hydratase mutations. J Clin Endocrinol Metab 2006:91:3071 - 5.

7. Brandon M, Baldi P, Wallace DC. Mitochondrial mutations in cancer. Oncogene 2006;25: 4647-62.

8. Chatterjee A, Mambo E, Sidransky D. Mitochondrial DNA mutations in human cancer. Oncogene 2006;25: 4663-74.

9. Czarnecka AM, Golik P, Bartnik E. Mitochondrial 
DNA mutations in human neoplasia. J Appl Genet 2006:47:67-78

10. Modica-Napolitano JS, Kulawiec M, Singh KK. Mitochondria and human cancer. Curr Mol Med 2007;7: $121-31$.

11. Petros JA, Baumann AK, Ruiz-Pesini E, et al. mtDNA mutations increase tumorigenicity in prostate cancer. Proc Natl Acad Sci U S A 2005:102:719-24.

12. Gasparre G, Porcelli AM, Bonora E, et al. Disruptive mitochondrial DNA mutations in complex I subunits are markers of oncocytic phenotype in thyroid tumors. Proc Natl Acad Sci U S A 2007;104:9001-6.

13. Baysal BE. Role of mitochondrial mutations in cancer. Endocr Pathol 2006;17:203-12.

14. Tickoo SK, Lee MW, Eble JN, et al. Ultrastructural observations on mitochondria and microvesicles in renal oncocytoma, chromophobe renal cell carcinoma, and eosinophilic variant of conventional (clear cell) renal cell carcinoma. Am J Surg Pathol 2000;24: $1247-56$.

15. Savagner F, Franc B, Guyetant S, et al. Defective mitochondrial ATP synthesis in oxyphilic thyroid tumors. J Clin Endocrinol Metab 2001;86:4920-5

16. Brooks JD, Marshall FF, Isaacs WB, Johns DR. Absence of Hinfl Restriction Abnormalities in Renal Oncocytoma Mitochondrial DNA. Mol Urol 1999;3: $1-3$.

17. Welter C, Kovacs G, Seitz G, Blin N. Alteration of mitochondrial DNA in human oncocytomas. Genes Chromosomes Cancer 1989;1:79-82.

18. Tallini G, Ladanyi M, Rosai J, Jhanwar SC. Analysis of nuclear and mitochondrial DNA alterations in thyroid and renal oncocytic tumors. Cytogenet Cell Genet 1994;66:253-9.

19. Meierhofer D, Mayr JA, Foetschl U, et al. Decrease of mitochondrial DNA content and energy metabolism in renal cell carcinoma. Carcinogenesis 2004;25: $1005-10$.

20. Rustin P, Chretien D, BourgeronT, et al. Biochemical and molecular investigations in respiratory chain deficiencies. Clin Chim Acta 1994;228:35-51.

21. Mayr JA, Paul J, Pecina $P$, et al. Reduced respiratory control with ADP and changed pattern of respiratory chain enzymes as a result of selective deficiency of the mitochondrial ATP synthase. Pediatr Res 2004; 55:988-94.

22. Zerbetto E, Vergani L, Dabbeni-Sala F. Quantification of muscle mitochondrial oxidative phosphorylation enzymes via histochemical staining of Blue Native polyacrylamide gels. Electrophoresis 1997;18: 2059-64.

23. Meierhofer D, Mayr JA, Ebner S, Sperl W, Kofler B. Rapid screening of the entire mitochondrial DNA for low-level heteroplasmic mutations. Mitochondrion 2005:5:282-96.

24. Meierhofer D, Mayr JA, Fink K, et al. Mitochondria DNA mutations in renal cell carcinomas revealed no general impact on energy metabolism. Br J Cancer 2006;94:268-74.

25. Benard G, Faustin B, Passerieux E, et al. Physiological diversity of mitochondrial oxidative phosphorylation. Am J Physiol Cell Physiol 2006;291:C1172-82.

26. Simonnet H, Demont J, Pfeiffer K, et al. Mitochondrial complex $\mathrm{I}$ is deficient in renal oncocytomas. Carcinogenesis 2003;24:1461-6.

27. Pronicki $M$, Sykut-Cegielska J, Mierzewska $\mathrm{H}$, et al Diversity of clinical symptoms in A3243G mitochondrial DNA mutation (MELAS syndrome mutation). Med Sci Monit 2002;8:CR767-73.

28. Lorenc A, Bryk J, Golik P, et al. Homoplasmic MELAS A3243G mtDNA mutation in a colon cancer sample. Mitochondrion 2003:3:119-24.

29. Hofhaus G, Attardi G. Lack of assembly of mitochondrial DNA-encoded subunits of respiratory $\mathrm{NADH}$ dehydrogenase and loss of enzyme activity in a human cell mutant lacking the mitochondrial ND4 gene product. EMBO J 1993;12:3043-8.

30. Maximo V, Soares $P$, Lima J, Cameselle-Teijeiro J Sobrinho-Simoes M. Mitochondrial DNA somatic mutations (point mutations and large deletions) and mitochondrial DNA variants in human thyroid pathology: a study with emphasis on Hurthle cell tumors. Am J Pathol 2002;160:1857-65

31. Ogilvie I, Kennaway NG, Shoubridge EA. A molecular chaperone for mitochondrial complex I assembly is mutated in a progressive encephalopathy. J Clin Invest 2005;115:2784-92.

32. Paner GP, Lindgren V, Jacobson $K$, et al. High incidence of chromosome 1 abnormalities in a series of 27 renal oncocytomas: cytogenetic and fluorescence in situ hybridization studies. Arch Pathol Lab Med 2007;131:81-5.

33. Vocke CD, YangY, Pavlovich $C P$, et al. High frequency of somatic frameshift BHD gene mutations in BirtHogg-Dube-associated renal tumors. J Natl Cancer Inst 2005;97:931 -5.

34. Baba M, Hong SB, Sharma N, et al. Folliculin encoded by the BHD gene interacts with a binding protein, FNIP1, and AMPK, and is involved in AMPK and mTOR signaling. Proc Natl Acad Sci U S A 2006; 103:15552-7

35. Maximo V, Botelho T, Capela J, et al. Somatic and germline mutation in GRIM-19, a dual function gene involved in mitochondrial metabolism and cell death, is linked to mitochondrion-rich (Hurthle cell) tumours of the thyroid. Br J Cancer 2005;92:1892-8.
36. Bonora E, Porcelli AM, Gasparre G, et al. Defective oxidative phosphorylation in thyroid oncocytic carcinoma is associated with pathogenic mitochondria DNA mutations affecting complexes I and III. Cancer Res 2006:66:6087-96.

37. Ricci JE, Munoz-Pinedo C, Fitzgerald P, et al. Disruption of mitochondrial function during apoptosis is mediated by caspase cleavage of the $\mathrm{p} 75$ subunit of complex I of the electron transport chain. Cell 2004 117:773-86

38. Shidara $Y$ Yamagata $K$, Kanamori $T$, et al. Positive contribution of pathogenic mutations in the mitochondrial genome to the promotion of cancer by prevention from apoptosis. Cancer Res 2005;65: $1655-63$.

39. Tan DJ, Chang J, Chen WL, et al. Somatic mitochondrial DNA mutations in oral cancer of betel quid chewers. Ann N Y Acad Sci 2004;1011:310-6.

40. Alonso A, Martin P, Albarran $C$, et al. Detection of somatic mutations in the mitochondrial DNA contro region of colorectal and gastric tumors by heteroduplex and single-strand conformation analysis. Electrophoresis 1997;18:682-5

41. Kose K, HiyamaT, Tanaka S, et al. Somatic mutations of mitochondrial DNA in digestive tract cancers. J Gastroenterol Hepatol 2005;20:1679-84.

42. Wang Y, Liu VW, Tsang PC, et al. Microsatellite instability in mitochondrial genome of common female cancers. Int J Gynecol Cancer 2006;16 Suppl 1 : 259-66.

43. Habano W, Nakamura $S$, Sugai T. Microsatellite in stability in the mitochondrial DNA of colorectal carcinomas: evidence for mismatch repair systems in mitochondrial genome. Oncogene 1998;17:1931 - 7 .

44. Tiranti V, Chariot $P$, Carella F, et al. Maternally inherited hearing loss, ataxia and myoclonus associated with a novel point mutation in mitochondrial tRNA Ser(UCN) gene. Hum Mol Genet 1995;4:1421 - 7 .

45. Hutchin TP, Thompson KR, Parker M, et al. Prevalence of mitochondrial DNA mutations in childhood/ congenital onset non-syndromal sensorineural hearing impairment. J Med Genet 2001;38:229-31.

46. Tiranti $\mathrm{V}$, Corona $\mathrm{P}$, Greco $\mathrm{M}$, et al. A novel frame shift mutation of the mtDNA COIII gene leads to impaired assembly of cytochrome $c$ oxidase in a patient affected by Leigh-like syndrome. Hum Mol Genet 2000;9:2733-42.

47. Nagy A, Wilhelm M, Kovacs G. Mutations of mtDNA in renal cell tumours arising in end-stage renal disease. J Pathol 2003;199:237-42.

48. Polyak K, LiY, Zhu H, et al. Somatic mutations of the mitochondrial genome in human colorectal tumours. Nat Genet 1998;20:291 -3. 